\title{
Should SAGES advance minimally invasive surgery in space?
}

\author{
Daniel M. Buckland • Daniel B. Jones
}

Published online: 25 October 2011

(C) Springer Science+Business Media, LLC 2011

With the recent completion of the Space Shuttle program, the National Aeronautics and Space Administration (NASA) and the rest of the American spaceflight community are designing new ways to reach space. Confusion in the popular press had led to the misconception that the Obama administration has ended the American human spaceflight program. In fact, the Obama administration (through the US Human Spaceflight Plans Committee or "Augustine Commission" [1]) realized that NASA did not have enough resources to both operate the space shuttle and design and build the next generation of space vehicles needed to accomplish the goals of the Bush administration's 2004 Vision For Space Exploration [2]. So, while work on mission design and decisions about whether future space vehicles will be made by NASA or private industry progress, the US Space Program will purchase seats on Russian Soyuz vehicles for transport to and from the International Space Station.

Regardless of the final design and system chosen, the crew selected to fly in space will have medical concerns. If the mission is to Mars or a near-Earth object (NEO), where the total mission time can be 3 years or longer, those medical concerns will have surgical implications that need to be addressed in-flight to complete the mission, or simply to get everyone back to Earth. According to NASA,

D. M. Buckland $(\bowtie) \cdot$ D. B. Jones

Harvard Medical School, Boston, MA, USA

e-mail: buckland@mit.edu

D. M. Buckland

Massachusetts Institute of Technology, Cambridge, MA, USA

D. M. Buckland · D. B. Jones

Beth Israel Deaconess Medical Center, Boston, MA, USA

D. B. Jones

SAGES Board of Governors, Los Angeles, CA, USA preventive medicine is the key approach to preventing a mission-impacting medical issue, but even the best screening only reduces risk; it does not eliminate it. Also, a goal of space exploration is to allow humans to live and work in space for the long term.

Over the last two decades, the Society of American Gastrointestinal and Endoscopic Surgeons (SAGES) has promoted the research and clinical adaptation of many technologies such as endoscopy, laparoscopy, robotic surgery, and natural orifice translumenal endoscopic surgery (NOTES). Besides publishing a few articles dealing with research in parabolic aircraft (also known as the "vomit comet," Fig. 1) and remote environments, SAGES has done little to be involved in the next frontier of surgical practice. Is it time to rethink our focus? Browning said that our "reach should exceed [our] grasp, or what's a heaven for?" [3]. SAGES should use exploration of the heavens to extend the reach of surgical technology beyond what we can currently grasp.

NASA's latest reference mission to Mars would take about 3 years; there would be about 6-8 months of transit time to Mars, 18 months on Mars, and 6-8 months to return. With a well-selected prescreened crew, the types of medical and surgical issues considered for contingency planning would be trauma from accidents and typical renal and abdominal pathologies for healthy 30-55-year-old men and women at risk for dehydration (from the low-pressure, low-humidity flight environment), fluid shifts (from weightlessness), and bone and muscle loss (disuse atrophy) [4]. The current protocol for the International Space Station is to return the crew-member to Earth for treatment as soon as safety allows for anything more than a minor medical issue. This would not be an option for a Mars mission, and even a Moon mission would have much more limited return capability. 


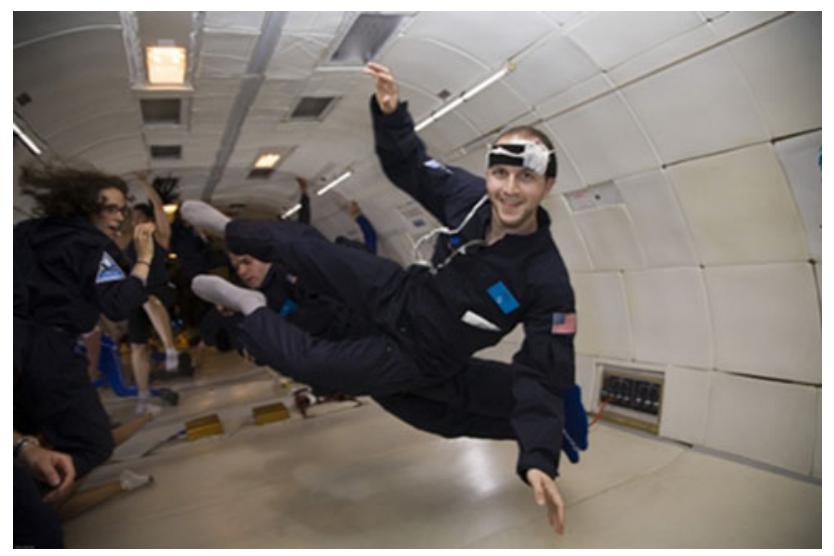

Fig. 1 The author while performing an ultrasound research experiment on a parabolic aircraft flight (image credit: Steve Boxall)

The spaceflight and Martian colony environment have several limitations that must be considered when compared with a medical treatment facility on Earth. First and foremost, the mass and volume budgeted for medical equipment in the design of spacecraft, such as instruments, fluids, and medications, are quite limited, and the resupply capability even more so. Optimal equipment should be reusable, reliable, repairable, storable, and able to be used for multiple types of procedures. Many of these limitations are similar to those encountered in remote or austere medical environments such as wilderness and combat medicine. During transit to and from Mars, the weightless environment also has different thermal and gas diffusion considerations. Since there are not normal convective currents in the air flow (i.e., heat does not rise when there is no "up"), active airflow must be maintained around the patient and possibly in the patient during insufflation to prevent buildup of heat and oxygen pockets that could lead to a fire hazard. Mars itself has less gravity than Earth, and it is currently unknown how this would change treatment efficacy, as it is difficult to simulate the gravity environment of Mars for more than 20-30 s at a time in a parabolic aircraft. Complete weightlessness such as that encountered during transit is experienced on the International Space Station, which can serve as a test bed for technologies designed for a Martian transit.

JD Polk, the Chief of Space Medicine at NASA's Johnson Space Center, describes six tenets that must be addressed with any medical system designed for spaceflight: mass, power, volume, time, cost, and risk [5]. For a technology to be considered for spaceflight, it must not increase more than two of the tenets, while hopefully reducing at least one. Minimally invasive surgery (MIS) should fit this paradigm, as it reduces risk (compared with open surgery) mass (fluid requirements), and time (recovery). However, it could increase volume and power (needed equipment), and possibly cost.
In 2009 Kirkpatrick and colleagues used a porcine model in a parabolic aircraft that could simulate both microgravity (spaceflight) and hypergravity ( $\sim 2$ times Earth gravity) to determine if there were physiologic constraints due to the insufflation necessary to produce abdominal hypertension, and found that the effect of microgravity was in fact to obviate the decrease in tidal volume accompanied by laparoscopic procedures on the ground [6].

Campbell and other flight surgeons associated with NASA reported in two papers $[7,8]$ in this journal the results of parabolic experiments in endoscopy and laparoscopy. Both reports showed a longer time to complete surgical tasks in a porcine model, but this was attributed to the novel environment, something that could possibly be attenuated with more training. Visualization was also found to not be as problematic as anticipated, because blood and other fluids in the cavity adhered to the bowel and other organs rather than floating free. Other studies [9] have done standard basic laparoscopic exercises in parabolic flight and found similar results.

In 2010 a team at the Arctic Circle performed a successful simulated laparoscopic appendectomy while consulting a mission control team at Henry Ford Hospital in Detroit [10]. To simulate a Mars mission, a 15-min delay was put into the communication between Mars (Arctic Circle) and the ground (Detroit). Along with voice communication, ultrasound imaging and the laparoscopic video feed were transmitted between locations. This allowed for telemedicine consultation, but the time delay involved in signal transmission prevented any "ground"-based operation of the remote procedure.

As laparoscopic instruments become more miniaturized and procedures become more advanced, greater options will be available for contingency planning. While previously the best option would have been management, future spaceflight mission design might include treatment as an option. This allows for greater allowance of preexisting medical conditions that would in the past be disqualifying for flight. Therefore, research should be directed at both finding ways to miniaturize and increase the portability of existing laparoscopic technology as well as better defining the safety envelope of medical and surgical conditions that can be treated by taking those technology advancements into account. This would further inform crew selection criteria and hopefully make spaceflight medical practice more closely resemble ground-based surgical and medical capability.

Specialized organizations such as the Aerospace Medicine Association are already working to develop recommendations and requirements for medical care in spaceflight [11]. NASA and private industry are now concentrating their efforts to design and build the next generation of space 
vehicles, making it the optimal time for SAGES to contribute knowledge and experience at the moment when it could have the greatest impact. In 2005 SAGES created the Military Working Group to address MIS in hostile environments and issues of retraining in advanced laparoscopy after deployment to the battlefield, and to promote collaboration with our members who serve and the wider military medical community. As we push into the next frontier of exploration, should SAGES not also collaborate with NASA or other space organizations to promote safer space travel so someday we can all boldly go where surgery has not gone before?

Disclosures Drs. Buckland and Jones have no conflicts of interest or financial ties to disclose.

\section{References}

1. Seeking a Human Spaceflight Program Worthy of a Great Nation (2009) Final report of the review of U.S. Human Spaceflight Plans Committee. NASA, Washington, DC

2. The Vision for Space Exploration (2004) NASA, Washington, DC
3. Browning R. Andrea del Sarto, line 98

4. NASA Human Research Roadmap (2011) http://humanresearch roadmap.nasa.gov/Risks/. Accessed 11 August 2011

5. Polk JD (2011) http://www.spacepolicyonline.com/pages/images/ stories/Polk_microg_aug_09.pdf. Accessed 11 August 2011

6. Kirkpatrick AW, Keaney M, Hemmelgarn B, Zhang J, Ball CG, Groleau M, Tyssen M, Keyte J, Campbell MR, Kmet L, McBeth $\mathrm{P}$, Broderick TJ (2009) Intra-abdominal pressure effects on porcine thoracic compliance in weightlessness: implications for physiologic tolerance of laparoscopic surgery in space. Crit Care Med 37:591-597

7. Campbell MR, Billica RD, Jennings R, Johnston S (1996) Laparoscopic surgery in weightlessness. Surg Endosc 10:111-117

8. Campbell MR, Kirkpatrick AW, Billica RD, Johnston SL, Jennings R, Short D, Hamilton D, Dulchavsky SA (2001) Endoscopic surgery in weightlessness: the investigation of basic principles for surgery in space. Surg Endosc 15:1413-1418

9. Panait L, Broderick T, Rafiq A, Speich J, Doarn CR, Merrell RC (2004) Measurement of laparoscopic skills in microgravity anticipates the space surgeon. Am J Surg 188:549-552

10. Otto C, Comtois JM, Sargsyan A, Dulchavsky A, Rubinfeld I, Dulchavsky S (2010) The Martian chronicles: remotely guided diagnosis and treatment in the Arctic Circle. Surg Endosc 24:2170-2177

11. Ad Hoc Committee of Members of the Space Medicine Association and the Society of NASA Flight Surgeons (2008) Human health and performance for long-duration spaceflight. Aviat Space Environ Med 79:629-635 